\title{
Social Protection in a Matching Model: The Case of Basic Income
}

\author{
Samir Amine ${ }^{1}$, Pedro Lages Dos Santos ${ }^{2}$ \\ ${ }^{1}$ Université du Québec en Outaouais, Cirano, Canada \\ ${ }^{2}$ Université du Havre, Le Havre, France \\ Email:samir.amine@uqo.ca
}

Received August 22, 2011; revised September 30, 2011; accepted October 8, 2011

\begin{abstract}
Faced with increasing poverty and the relative inefficiency of their redistribution systems, many countries are turning to new instruments of social policy. Many economists found there an opportunity to present the mechanism of basic income as the new way forward by the modern social protection. We show that, in a matching model with differentiation agents, the introduction of the basic income has no effect on the balance of the labor market.
\end{abstract}

Keywords: Basic Income; Matching; Social Protection

\section{Introduction}

In recent years, the redistributive system in developed countries has shown its limits against the development of unemployment and, more generally, given the socio-economic changes in our society over the last thirty years. This has naturally led to consider other approaches to social protection and, in particular, income security (Pissarides [1]). Many economists, including Atkinson [2] and Ferry [3], found there an opportunity to present the mechanism of basic income as the new way forward by the modern social protection. This type of measure is seen as an alternative to Beveridge and Bismarckian conceptions which could alleviate many problems of the current tax system.

Adverse effects on employment of unemployment benefits and social benefits in general have been widely shown in the WS-PS models or in matching models of Pissarides [4]. Many studies (Cheron [5]) have shown in different analytical frameworks for the benefit of replacing the current system of unemployment compensation through a system of basic income. However, the results of these studies often have some confusion. Indeed, it is not uncommon that they attribute to basic income properties that are due either to a policy of replacing a given system by a system of basic income, or to its financing system. In this paper, we show that introducing a basic income may have positive effects in terms of poverty reduction (absolute), but is neutral on the labor market equilibrium and we cannot expect a direct effect on unemployment. These results are obtained through a matching model with horizontal differentiation agents.
This article is organized as follows. In Section 2, we present our theoretical model. Sections 3 and 4 present the model resolution and comparative statics. The last section concludes the paper.

\section{A Theoretical Analysis of Basic Income}

Consider an economy populated by firms and workers $(N$ workers). The two agents are risk-neutral and have the same rate of time preference denoted by $r$ (and $R$ is the sum of $(1+r)$ ). Firms in this economy produce the same good but offer a single heterogeneous job. The exogenous job destruction rate is $s$. Nevertheless, we assume firm free-entry in order to maintain a fixed number of firms at the stationary state. Likewise, workers are heterogeneous and have an infinite horizon. Note that to highlight the specific effects of basic income, we assume (implicitly) that it is financed by a tax neutral.

\subsection{Differentiation and Productivity}

First, In order to describe the differentiation of workers and jobs, I use the analysis tool of Salop [6]. Workers and firms are uniformly distributed along a circle of length equal to two. The location of a worker on this circle represents his skill type. Likewise, the position of a firm on the circle represents its type that is the skill which perfectly suits its needs.

Let, $l$, represents the distance between both positions $(0 \leq l \leq 1)$. This distance measures the mismatch between skill type of worker and firms optimal needs. If the match is perfect, this distance is equal to zero $(l=0)$. On the contrary, in the case of total mismatch between the two 
agents, this distance is equal to the unit $(l=1)$. Consequently, productivity $y(l)$ of job is a decreasing function in the distance $l\left(y^{\prime}(l)<0\right.$ and $\left.y^{\prime \prime}(l) \leq 0\right)$.

In accordance with intuition, all matches will not be acceptable. Each firm of this economy defines a maximal mismatch, called $\lambda$, for recruiting a worker. Indeed, above this mismatch threshold the two agents will reject a match.

\subsection{Utilities and Profits}

The When a worker gets a job, productivity and therefore his salary (gross) $w(l)$ depend on the distance $l$ between his skill type and the position (needs) of firm that hired him. The lifetime utility of such a worker is denoted by $W_{E}(l)$. Concerning the unemployed, we assume that they do not receive unemployment benefits. Their lifetime utility $W_{U}$ depends on the threshold $\lambda$ (at this stage of the analysis $\lambda$ is given) which affects probability of finding a job $p$ and the expected lifetime utility $\bar{W}_{E}$ of a worker who gets a job. As, the distribution of firms is uniform, this expected utility is given by:

$$
\bar{W}_{E}=\frac{1}{\lambda} \int_{0}^{\lambda} W_{E}(l) \mathrm{d} l
$$

We assume that all agents (employed or unemployed) receive a basic income denoted $\mu$. Thus, in a stationary state, the lifetime utilities $W_{E}(l)$ and $W_{U}$ satisfy:

$$
\begin{gathered}
W_{E}(l)=w(l)+\mu+R^{-1}\left[s W_{U}+(1-s) W_{E}(l)\right] \\
W_{U}=\mu+R^{-1}\left[p \bar{W}_{E}+(1-p) W_{U}\right]
\end{gathered}
$$

The utility of an employed depends on both its instantaneous income (wage and basic income) and its expected lifetime utility due to the fact or not to retain his job in the future. The utility of an unemployed depends on the amount of basic income and on the probability of finding a job.

Concerning firms, we consider that the jobs are either vacant or filled. I note $J_{F}(l)$ the value of filled job and $J_{V}$ the value of vacant job. $J_{F}(l)$ satisfies:

$$
J_{F}(l)=y(l)-w(l)+R^{-1}\left[s J_{V}+(1-s) J_{F}(l)\right]
$$

The value of a filled job depends on the instantaneous gain and on future profits conditioned by the possibility that the company disappears. Thus, on the one hand, the value of the filled job is growing, obviously, with productivity and decreases with the wage paid to the employed (note that productivity and wage depend on the mismatch between the qualification held by the employed and one that would suit the firm). On the other hand, this value $J_{F}(l)$ decreases the probability of a possible separation between the firm and the employed. The value of a vacant job $J_{V}$ is a function of the threshold $\lambda$. This threshold affects the probability $q$ to fill jobs as well as the expected value, $\bar{J}_{F}$, of the job:

$$
\begin{gathered}
\bar{J}_{F}=\frac{1}{\lambda} \int_{0}^{\lambda} J_{F}(l) \mathrm{d} l \\
J_{V}=-c+R^{-1}\left[q \bar{J}_{F}+(1-q) J_{V}\right]
\end{gathered}
$$

As long its job is not filled, firm must invest $c$ to create this job and to look for a worker. Furthermore, opening a new job is more profitable if the probability $q$ is high. Taking into account of the free-entry assumption, I admit that new jobs will be created until the optimal value of the vacant job $\left(J_{V} \geq 0\right)$ be equal to zero:

$$
J_{V}=0
$$

In addition, the job average productivity $\bar{y}$ and average wage $\bar{w}$ are given by:

$$
\begin{aligned}
& \bar{y}=\frac{1}{\lambda} \int_{0}^{\lambda} y(l) \mathrm{d} l \\
& \bar{w}=\frac{1}{\lambda} \int_{0}^{\lambda} w(l) \mathrm{d} l
\end{aligned}
$$

Using Equations (4)-(7), we obtain:

$$
\begin{aligned}
& \bar{J}_{F}=\frac{R(\bar{y}-\bar{w})}{r+s} \\
& \bar{J}_{F}=\frac{R c}{q}
\end{aligned}
$$

It therefore appears that in equilibrium, given the condition of free-entry of firms, the average value of a filled job depends on both the expected future profitability (the difference between productivity and labor costs) but on the profit made through the keep (or creation) of vacant jobs. Thus, the expected value of filled job increases with its instantaneous mean return and with the cost of a vacant job and decreases with the separation rate and the probability of filling a vacancy.

\subsection{Wage Bargaining and Surplus Sharing}

In accordance with usual matching models, surplus created by a firm/worker is divided between the two agents according to their respective bargaining strength. However, Generalized Nash rule is constrained here by giving the worker a wage higher than the minimum wage $(m)$. In fact, if $\beta(0<\beta<1)$ represents the workers' bargaining strength, the optimization program for firm is:

$$
\operatorname{Max} \beta \ln \left[W_{E}(l)-W_{U}\right]+(1-\beta)\left[J_{F}(l)-J_{V}\right]
$$

Therefore, the global surplus, noted $S(l)$, is divided between the two agents according to the Nash rule:

$$
\begin{gathered}
W_{E}(l)-W_{U}=\beta\left[W_{E}(l)+J_{F}(l)-W_{U}-J_{V}\right] \\
J_{F}(l)-J_{V}=(1-\beta)\left[W_{E}(l)+J_{F}(l)-W_{U}-J_{V}\right]
\end{gathered}
$$


In addition, to be accepted matches must generate a positive global surplus and so satisfy the following condition:

$$
W_{E}(l)+J_{F}(l)-W_{U}-J_{V} \geq 0
$$

Consequently, the mismatch threshold $\lambda$ cancels the global surplus:

$$
W_{E}(\lambda)+J_{F}(\lambda)-W_{U}-J_{V}=0
$$

Taking into account Equations (15), (12) and (13), we deduce:

$$
\begin{aligned}
& W_{E}(\lambda)=W_{U} \\
& J_{F}(\lambda)=J_{V}
\end{aligned}
$$

According to the sharing rule, we deduce that $\lambda$ is the hiring threshold. Obviously, $\lambda$ is defined such as the rent of the least productive employee is null. Then, $\lambda$ constitute an optimal stop rule of research for firms and workers. Taking into account the free-entry condition, we have:

$$
y(\lambda)=w(\lambda)
$$

We can establish the following result:

Proposition 1. The lowest wage (reservation wage) is equal to the productivity of the job held by worker located at the greatest distance possible to the firm (i.e. the worst matching possible).

\subsection{Hiring Process}

In order to give more solid microeconomic foundations to the meeting process between workers and firms and thus to the problem of the frictions on the labor market, we hold a reformulation of the "urn ball model" (Petrongolo and Pissarides [7], Albrecht, Gautier and Vroman [8]). For $\lambda \leq x$, the probability to fill a vacant job, denoted $q$, is given by:

$$
q=1-e^{-\frac{\lambda}{x \theta}}
$$

The probability to be hired, denoted $p$, satisfies:

$$
p=\left(1-e^{-\frac{\lambda}{x \theta}}\right) \theta
$$

This probability $p$ is an increasing function of the threshold $\lambda$ and decreasing of $x$. We show that $p$ is also an increasing function of the labor market tightness $\theta$. Consequently, an increase of the threshold $\lambda$ provokes at the same time increases of $p$ and $q$. However, it can turn out socially unwanted because workers can be then hired for jobs where they are less productive (increasing the number of "bad" matches) provoking a decrease of the average productivity $\bar{y}$.

In the stationary equilibrium, the number of workers who lose their job must equal the number of unemployed workers who find a job. Let $L$ the employment level, we have

$$
p U=s L=s(N-U)
$$

This condition implies that the equilibrium unemployment rate $\mathrm{u}$ is a function of the labor market tightness:

$$
u=\frac{s}{s+p}
$$

\section{Model Equilibrium}

Solving the model consists of establishing interactions at the stationary equilibrium, between labor market tightness $\theta$ and mismatch threshold $\lambda$. We first study and specify the optimal choices of job specialization and selectivity. Then, using the wage setting and the surplus sharing rule, we introduce the labor market tightness. The last expression between endogenous variables of the model is deduced from the job creation process (Amine and Lages [9] and [10]).

\subsection{Selectivity and Labor Market Tightness}

Using Equation (2), we establish:

$$
W_{E}(\lambda)=w(\lambda)+\mu-R^{-1}\left[s W_{U}+(1-s) W_{E}(\lambda)\right]
$$

Taking into account $W_{E}(\lambda)=W_{U}$ and $w(\lambda)=y(\lambda)$, we obtain:

$$
r W_{U}=R[y(\lambda)+\mu]
$$

Given Equation (3), we have:

$$
r W_{U}=R \mu+p\left[\bar{W}_{E}-W_{U}\right]
$$

Then, we deduce:

$$
y(\lambda)=R^{-1} p\left[\bar{W}_{E}-W_{U}\right]
$$

Using Equations (11), (12) and (13), we establish:

$$
\bar{W}_{E}-W_{U}=\frac{\beta}{1-\beta} \bar{J}_{F}=\frac{\beta}{1-\beta} \frac{R c}{q}
$$

Therefore, (26) and (25) give:

$$
y(\lambda)=\frac{\beta}{1-\beta} c \theta
$$

We establish the first decreasing relationship between labor market tightness $\theta$ and mismatch threshold $\lambda$ (WS curve, Figure 1).

\subsection{Job Creation}

Considering Equations (12), (13) and (10), we can determine the workers shares:

$$
\bar{W}_{E}-W_{U}=\frac{\beta}{1-\beta} \bar{J}_{F}=\frac{\beta}{1-\beta} \frac{R(\bar{y}-\bar{w})}{r+s}
$$


This expression is used to reflect inequality among workers. However, the expected utility of an employed is written:

$$
\bar{W}_{E}=\bar{w}+\mu+R^{-1}\left[s W_{U}+(1-s) \bar{W}_{E}\right]
$$

A worker can expect to receive, if hired, in addition to basic income, a wage equal to $\bar{w}$. Given Equations (2), (3), (26) and (28) we can then write:

$$
\bar{w}=\beta \bar{y}+\beta c \theta
$$

Equations (26) and (28) determine the expression of the average wage:

$$
\bar{w}=\bar{y}-\frac{(r+s) c}{q}
$$

Given Equation (27) and (29), we establish the wage setting expression:

$$
\bar{w}=\bar{y}-(1-\beta)[\bar{y}-y(\lambda)]
$$

In the equilibrium, the wage-setting must be consistent with the jobs creation process (Equation (30)), the pair ( $\theta$; ג) must satisfy:

$$
(1-\beta) q[\bar{y}-y(\lambda)]=(r+s) c
$$

This expression gives a second relationship between the mismatch threshold and the labor market tightness. Given the concavity of $y(l)$, it follows that the difference $\bar{y}-y(\lambda)$ is an increasing function with the threshold $\lambda$. Therefore, the increase $\lambda$ causes the increase of the probability $q$ to fill a vacancy and of the labor market tightness $\theta$ ( $J C$ curve, Figure 1). Furthermore, it appears, obviously, that basic income has no effect either on the second relationship between the mismatch threshold and the labor market tightness.

\section{Comparative Statics}

The equilibrium model satisfies the relations (27) and (32).

Definition. The labor market equilibrium is a set of variables $\left(\lambda^{*} ; \theta^{*}\right)$ which jointly satisfy Equations (27) and (32).

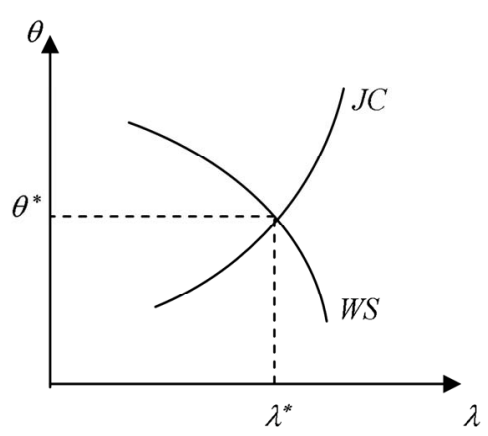

Figure 1. The stationary equilibrium.
Figure 1 presents this equilibrium. Using $\left(\lambda^{*} ; \theta^{*}\right)$, we deduce the equilibrium values of other variables in this economy.

It therefore seems so obvious, that the introduction of basic income has no effect on the equilibrium $\left(\lambda^{*} ; \theta^{*}\right)$. We can then state the following proposition:

Proposition 2. The introduction of a basic income, financed by a neutral tax in a matching model with horizontal differentiation of qualifications, has no direct effect on the economy equilibrium.

Therefore, it appears that in our analytical framework, we cannot conclude to any direct effect of basic income on employment. However, if we had introduced unemployment benefits, we could have found that replacing the system of unemployment benefits through a system of basic income can be conducive to employment. Moreover, if we had considered that it was funded by a nonneutral tax, we would also have contracted with an effect on unemployment.

\section{Conclusions}

Historically, opinions differ among strong supporters of basic income and opponents. Anyway, most of his supporters consider mainly basic income as an effective way to improve the tax systems while struggling against poverty. However, some attribute to him many more benefits. So many people think that basic income allows, among other things, to raise wages, reduce inequality and especially the fight against unemployment.

Now we stand for, in this paper, that the effects attributed to basic income in some works may not be directly charged. Indeed, the positive impact on employment is due, mostly, to replacing an existing system with a basic income. In this case, it is the removal of an existing system (unemployment benefits, for example) harmful to employment and not the introduction of basic income which induces a positive effect on employment.

In addition, we support our argument by introducing a basic income in a matching model with horizontal differentiation agents. We then show that such a measure has no effect on the labor market equilibrium and in particular on employment. Moreover, according to this conclusion, some economists consider this neutrality as a best argument in defense of basic income.

\section{REFERENCES}

[1] C. Pissarides, "Why Do Firms Offer 'Employment Protection'?” Economica, Vol. 77, No. 308, 2010, pp. 613636. doi:10.1111/j.1468-0335.2010.00861.x

[2] A. B. Atkinson, "Public Economics in Action: The Basic Income Flat Tax Proposal," Clarendon Press, Oxford, 1995.

[3] J. M. Ferry, "L'Allocation Universelle. Pour un Revenu 
de Citoyenneté," Cerf, Paris, 1995.

[4] C. Pissarides, "Equilibrium Unemployment Theory," MIT Press, Cambridge, 2007.

[5] A. Chéron, "Allocation Universelle vs. Indemnités Chômage: Une Evaluation Quantitative dans un Modèle D'appariement," Revue Economique, Vol. 53, No. 5, 2002, pp. 951-964.

[6] S. Salop, "Monopolistic Competition with Outside Goods," Bell Journal of Economics, 1976.

[7] B. Petrongolo and C. Pissarides, "Looking into the Black Box: A survey of the Matching Function," Journal of Economic Literature, Vol. 39, No. 2, 2001, pp. 390-431. doi:10.1257/jel.39.2.390
[8] J. Albrecht, P. Gautier and S. Vroman, "Matching with Multiple Applications," Economics Letters, Vol. 78, No. 1, 2003, pp. 67-70. doi:10.1016/S0165-1765(02)00178-7

[9] S. Amine and P. Lages Dos Santos, "Technological Choices and Unemployment Benefits in a Matching Model with Heterogenous Workers," Journal of Economics, Vol. 101, No. 1, 2010, pp. 1-19. doi:10.1007/s00712-010-0133-4

[10] S. Amine and P. Lages Dos Santos, "The Influence of Labour Market Institutions on Job Complexity," Research in Economics, Vol. 65, No. 3, 2011, pp. 209-220. doi:10.1016/j.rie.2010.10.001 